\title{
Do EMS College Students Fit Enough for The Future Occupational?
}

\section{Dr/ Khalid S. Aljaloud}

\section{Abstract}

Emergency responders should be physically fit to perform strenuous duties perfectly and safely. The purpose of the present study was to assess student's occupational physical fitness in Prince Sultan bin Abdulaziz College for Emergency Medical Services (PSAC-EMS) in line with the international physical fitness guidelines for American Council on Exercise (ACE). Seventy-three EMS students randomly selected. Mean age and BMI were $(20.5+1.2)$ and $(26.6+6.3)$ respectively. Participants asked to perform three suggested physical fitness for (ACE). We used tests protocol and administrations to calculate percentages for student group comparing it with the testterminations criteria for (ACE). One sample t-test used to assess the differences between the obtained scores versus the reference scores. Results clearly showed a moderate to a strong correlation between most of the variables especially trunk flexor endurance test and trunk extensor endurance test $(\mathrm{r}=0.69, \mathrm{P}<0.01)$. In addition, there are a strong correlation between trunk lateral endurance (left side) and trunk lateral endurance (right side) tests $(\mathrm{r}=0.81, \mathrm{P}<0.01)$. In terms of ACE guidelines for EMS practitioners, results clearly showed that subjects of this study were not significant physically fit. This research concludes that students in (PSAC-EMS) need special exercise program focus primarily on the EMS responder's ability to fulfill their occupational requirements and to fulfill the mission of the (PSACEMS).

Key Words: Paramedics; EMS; Physical Fitness; Occupational; Prevention Test.

\section{Introduction}

Paramedics respond to emergency calls, performing physical effort due to the

nature of their occupational requirement such as doing $\mathrm{CPR}$, left and move patients or

Exercise Physiology Department, King Saud University, Saudi Arabia. Correspondence should be directed to Khalid S. Aljaloud, $\mathrm{PhD}$, King Saud University, Exercise Physiology Department, Riyadh 11451, P.O. Box: 2454

Assiut Journal For Sport Science Arts 
transporting patients to medical facilities quickly. Moreover, heavier patients need to provide extra effort to lift and maneuver them, which increase the potential of common injury such as lower back injury $(1,13)$.

Emergency medical services employees (EMTs) at higher risk of injuries comparing to the national average $(13,3)$. For instance, obese patients directly contribute to increasing levels of lifting-related injuries among EMS practitioners (10,13). Musculoskeletal injuries, especially back injuries, have shown to be a common cause of injury among EMTs; research on paramedics and work-related injuries confirms the cause for concern about the occupational risks associated with performing the work (8, 4-7). Data from previous study found that the majority of nonfatal injuries $(84 \%)$ involved sprains and strains, mostly in the hands and fingers, and $42 \%$ affected the lower trunk. Almost half of these incidents mainly because of lifting or moving the patient (8). These injuries urgently require the maintain level of the occupational physical fitness for safety and prevention. Paramedics should be physically fit to perform strenuous duties perfectly and safely $(9,12)$.

The

National

Association of Emergency Medical Technicians (NAEMT) American in collaboration with the Council on Exercise (ACE) has developed the physical fitness guidelines for EMTs (ACEfitness.org 2012) (10). These guidelines have been suggested to help reduce the number and musculoskeletal injuries related to the occupational tasks undertaken by EMTs and paramedics. Moreover, these guidelines used to screen paramedics to distinguish those who have a potentially increased risk for suffering movement-related injuries from those who are at less of a risk.

Prince Sultan bin Abdulaziz College for Emergency Medical Services (PSAC-EMS) at King Saud University is the first specialized colleges in the Kingdom of Saudi Arabia and 
in the Middle East to meet the growing need for specialists in emergency medical services. One of the main requirement to develop the students of the PSAC-EMS was to minimize the effects of accidental workrelated injuries. Thus, the main purpose of this study was to compare the student's occupational physical fitness in (PSAC-EMS) in line with the international physical fitness guidelines developed by ACE.

\section{Methods:}

Subjects

The present study is a cross-sectional descriptive study. One hundred and thirtynine male students from (PSAC-EMS) randomly selected to participate in the present study. The selection performed base on selection criteria which include 1. Academically enrolled in the university during the semester he participated in the study. 2 . Apparently healthy student. 3 . Not involve in any heavy exercise prior to the test of this study. 4. Have no recent injuries (during the last 6 months). 5. Do not take any medications that can affect the results of the tests that using in the study. All students read and signed a consent form and confirmed that they were healthy and agreed to participate in this study.

\section{Measures}

Physical characteristics including body mass, height and calculated body mass index were recorded using valid and reliable instrument in exercise physiology laboratory at the department of Exercise Physiology in King Saud University.

Three types of assessment were choosing from the American Council on Exercise (ACE) for the National Association of Emergency Medical Technicians (NAEMT) (ACEfitness.org 2012) (10). First, Stability Tests: 1. Storkstand Balance test (SB) to assess static balance by timing standing on one foot in a modified stork-stand position and categorize the student performance (Excellent, Good, Average, Fair, Poor) when they (>50 sec, 41-50 sec, 31-40 sec, 20-30 sec, <20) respectively. In addition, 2. Sharpened Romberg test (SR) to assess static balance and postural control while timing standing 
on a reduced base of support with removing visual sensory perception interpreted good postural control with more than 30 second and poor postural control is less than 30 second. (2-13).

Secondly, Core Function Test: McGill's Torso Muscular Endurance Test Battery (14). Involves complex movement patterns that continually change as a function of the three-dimensional torque needed to support the various positions of the body trunk. Which consist of 1. Trunk Flexor Endurance Test (Flexor) to assess muscular endurance of the deep core muscles which is a timed test involving a static, isometric contraction of the anterior muscles, stabilizing the spine until the individual exhibits fatigue and can no longer hold the assumed position. 2. Trunk Lateral Endurance Test (Lateral) to assess muscular endurance of the lateral core muscles on each side of the trunk that stabilize the spine. 3. Trunk Extensor Endurance Test (Extensor) to assess muscular endurance of the torso extensor muscles, and it is also a timed test involving an isometric contraction of the trunk extensor muscles that stabilize the spine. Clearly, each individual test in this testing battery was not a primary indicator of current or future back problems; McGill has proven that the relationships among the tests are important indicators of muscle imbalances that can lead to back pain. McGill suggests that Flexion/Extension ratio should be less than 1.0. Right-Side Bridge (RSB): Left-Side bridge (LSB) scores should be no greater than 0.05 from a balanced score of 1.0. Side Bridge (either side): extension ratio should be less than 0.75 . These ratios indicate balanced endurance among the muscle groups.

Finally, Stability and Mobility Tests: 1. Modified body-weight Squat Test (ST) to assess muscular fitness of the lower extremity when performing repetitions of a squat-to-stand movement at Knees flex $45^{\circ}-90^{\circ}$. 2. Front Plank (FP) to assess the core musculature's ability that hold the spine in neutral alignment when the body is in a forearm plank position. 3. Overhead Reach (OR) to assess the 
mobility of the shoulder joints in external rotation. All the ACE tests protocols, administrations, and general interpretations where considered during measuring stages and data collection.

Data Analysis

Results representative as mean, stander deviation (SD) and ratio. All data was statistically analyzed using IBM SPSS Statistics 24.0 program. One sample t-test used to compare the mean of each fitness test versus the international criteria for (ACE). Pearson correlation used to investigate the correlation between the fitness testes results versus body mass and BMI to find out the relationship between body composition and fitness level of the EMS participants. In Addition, percentage of EMS participants who achieved the acceptable scores of the ACE fitness tests criteria were calculated.

\section{Results}

Mean and stander deviation $( \pm \mathrm{SD})$ of age, body mass, height and body mass index (BMI) of total 139 subject shown in Table 1.

Table (1)

Physical Characteristics

\begin{tabular}{lllll}
\hline $\begin{array}{l}(\mathbf{n} \\
\mathbf{1 3 9})\end{array}$ & Age $(\mathbf{y})$ & $\begin{array}{l}\text { Body mass } \\
(\mathbf{k g})\end{array}$ & Height $(\mathbf{m})$ & BMI $\left(\mathbf{k g} / \mathbf{m}^{2}\right)$ \\
& $\begin{array}{l}20.5 \\
1.2\end{array}$ & $\pm 77.0 \pm 20.3$ & $1.73 \pm 0.07$ & $25.6 \pm 6.3$ \\
& & & & \\
\hline
\end{tabular}

Note. BMI: body mass index

ACE physical fitness tests results for (PSAC-EMS) students including stability tests, Core Function tests as well as stability and mobility tests illustrated in Table 2. Mean $( \pm \mathrm{SD})$ was compared to the ACE criteria for adult male. Results included reference scores or cutoff scores and percentage of participants who achieved the average score or above for each ACE physical fitness tests.

Table (2)

ACE Physical Fitness Tests ( $n=139)$.

\begin{tabular}{c|c|c|c}
\hline \hline Tests & $\begin{array}{c}\text { Mean } \\
\pm \text { SD }\end{array}$ & Reference Score & $\begin{array}{c}\% \\
\text { participants } \\
\text { apsed } \\
\text { average }\end{array}$ \\
\hline \hline
\end{tabular}




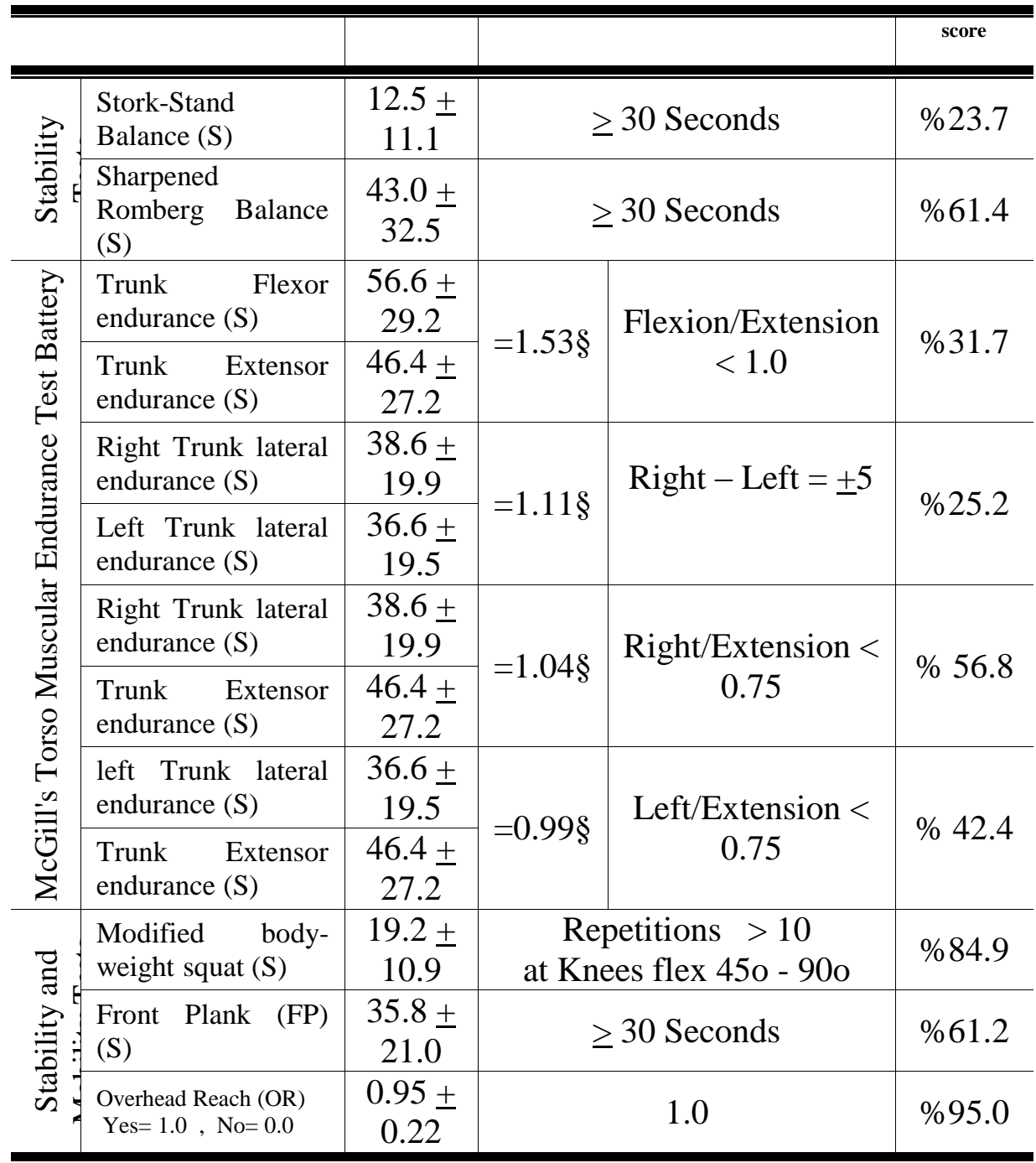

Note: $\$=$ Calculated: lateral endurance/Trunk

Flexion/Extension. Right trunk lateral endurance/Left trunk lateral endurance. Right trunk lateral endurance/Trunk Extensor endurance. Left trunk
Extensor endurance.

One sample $t$-test used to assess the differences between the obtained scores versus the reference scores that developed by the ACE. The results 
summarized in (Table 3). In terms of ACE guidelines for EMS practitioners, results clearly showed that subjects of this study were not significant physically fit. Especially the physical fitness related to the McGill's torso muscular endurance test battery.

Table (3)

T-test for the Stability, Core Function and Stability \& Mobility tests compared to the ACE Criteria for Adults male. $(n=139)$

\begin{tabular}{|c|c|c|}
\hline Test & Mean \pm SD & t value \\
\hline Stork-Stand Balance (S) & $12.5 \pm 11.1$ & $-15.64 *$ \\
\hline Sharpened Romberg Balance (S) & $43.0 \pm 32.5$ & $5.07 *$ \\
\hline Trunk Flexor endurance $(\mathrm{S})$ & $56.6 \pm 29.2$ & \multirow{2}{*}{$5.08 *$} \\
\hline Trunk Extensor endurance (S) & $46.4 \pm 27.2$ & \\
\hline Right Trunk lateral endurance (S) & $38.6+19.9$ & \multirow{2}{*}{$2.71 *$} \\
\hline Left Trunk lateral endurance (S) & $36.6+19.5$ & \\
\hline Right Trunk lateral endurance (S) & $38.6+19.9$ & \multirow{2}{*}{$4.87 *$} \\
\hline Trunk Extensor endurance (S) & $46.4+27.2$ & \\
\hline Left Trunk lateral endurance (S) & $36.6+19.5$ & \multirow{2}{*}{$4.11 *$} \\
\hline Trunk Extensor endurance (S) & $46.4+27.2$ & \\
\hline Modified body-weight squat (S) & $19.2+10.9$ & $10.04 *$ \\
\hline Front Plank (FP) (S) & $35.8+21.0$ & -0.11 \\
\hline Overhead Reach (OR) Yes $=1.0, \mathrm{No}=0.0$ & $0.95+0.22$ & -1.93 \\
\hline
\end{tabular}

* Significantly different from reference scores $(P<0.001)$

Correlation between

variables illustrated in Table 4. Results clearly showed a moderate to a strong correlation between most of the variables especially trunk flexor endurance test and trunk extensor endurance test $(r$ $=0.69, P<0.01)$. In addition, there is a strong correlation between trunk lateral endurance (left side) and trunk lateral endurance (right side) tests $(r=0.82, P<0.01)$. Furthermore, body composition data was negatively correlated to trunk lateral endurance tests (both left and right sides) as 
well as to the front plank test

$<0.05$ to $-0.445, P<0.01)$.

(range between $r=-0.287, P$

\section{Table (4)}

Pearson correlation to Stability, Core Function, and Stability \&

Mobility tests compared to the ACE Criteria for Adults male

\begin{tabular}{|c|c|c|c|c|c|c|c|c|c|c|}
\hline $\begin{array}{l}\mathrm{ACE} \\
\text { fitness } \\
\text { tests } \\
\end{array}$ & $\begin{array}{l}\text { Sharpened } \\
\text { Balance }\end{array}$ & $\begin{array}{l}\text { Trunk } \\
\text { Flexor }\end{array}$ & \begin{tabular}{|c|} 
Trunk \\
Lateral \\
Right \\
\end{tabular} & \begin{tabular}{|c|} 
Trunk \\
Lateral \\
Left \\
\end{tabular} & \begin{tabular}{|c|} 
Trunk \\
Extensor
\end{tabular} & $\begin{array}{c}\text { Squat } \\
\text { test }\end{array}$ & $\begin{array}{l}\text { Front } \\
\text { Plank }\end{array}$ & Overhead & $\begin{array}{l}\text { Body } \\
\text { mass }\end{array}$ & BMI \\
\hline $\begin{array}{l}\text { Sharpened } \\
\text { Balance }\end{array}$ & & .198 & $.449 * *$ & $.604 * *$ & $.328 *$ & $.308 *$ & $.527 * *$ & $-.034-$ & $\begin{array}{c}- \\
.356- \\
*\end{array}$ & $\begin{array}{c}-.287- \\
*\end{array}$ \\
\hline $\begin{array}{l}\text { Trunk } \\
\text { Flexor } \\
\end{array}$ & & & $.615 * *$ & $.406 * *$ & $.696 * *$ & $372 * *$ & .193 & .139 & $\begin{array}{c}- \\
.077-\end{array}$ & $-.127-$ \\
\hline $\begin{array}{l}\text { Right } \\
\text { Trunk } \\
\text { Lateral }\end{array}$ & & & & $.815 * *$ & $.495 * *$ & $433 * *$. & $471 * *$ & .114 & \begin{tabular}{|c|}
- \\
$.392-$ \\
$* *$
\end{tabular} & $\begin{array}{c}-.445- \\
* *\end{array}$ \\
\hline $\begin{array}{l}\text { Left } \\
\text { Trunk } \\
\text { Lateral }\end{array}$ & & & & & $.384 * *$ & $423 * *$ & $490 * *$ & .041 & \begin{tabular}{|c|} 
\\
$340-$ \\
$* *$
\end{tabular} & $\begin{array}{c}-.373- \\
* *\end{array}$ \\
\hline $\begin{array}{l}\text { Trunk } \\
\text { Extensor } \\
\end{array}$ & & & & & & .186 & .182 & .182 & \begin{tabular}{|c|}
- \\
$.189-$ \\
\end{tabular} & -.209 \\
\hline Squat test & & & & & & & $.494 * *$ & .153 & $\begin{array}{c}- \\
.014- \\
\end{array}$ & $-.091-$ \\
\hline $\begin{array}{l}\text { Front } \\
\text { Plank }\end{array}$ & & & & & & & & .044 & $\begin{array}{c}- \\
297- \\
*\end{array}$ & $\begin{array}{c}-.369- \\
* *\end{array}$ \\
\hline Overhead & & & & & & & & & \begin{tabular}{|c|}
- \\
$.181-$ \\
\end{tabular} & $-.191-$ \\
\hline $\begin{array}{l}\text { Body } \\
\text { mass } \\
\end{array}$ & & & & & & & & & & $.963 * *$ \\
\hline BMI & & & & & & & & & & \\
\hline
\end{tabular}

\section{Discussion}

The primary purpose of the present study was to compare physical fitness for a group of students in PSAC-

EMS with the international physical fitness guidelines developed by ACE. The results showed that participants 
characteristics were close to the average adult male of the ACE except a slight elevation in BMI (26.6 \pm 6.3). The mission of PSAC-EMS is to seek an excellent medical contribution through achieving the quality as a basis of reaching the excellence in line with international criteria. Results from this study highlight insufficient physical fitness for a sample of PSACEMS's students. Particularly, trunk muscular endurance did not meet the minimum level of the McGill's torso muscular endurance test recommendation $(7,14)$. Statistics indicated that mean scores of the trunk extensor endurance was lower than the mean scores of trunk flexor endurance and lower than the lateral trunk endurance (right and left sides). Moreover, the percentage of participants who pass the average (acceptable) score for the McGill's tests, were only \%31.7 for xtension/Flexion ratio and
$\% 25.2$ for Right/Left ratio, $\% 56.8$ for Right trunk/Extension and \%42.4 for Left trunk/Extension. Therefore, a number of students may be at risk of having lower back injury due to the weakness of their trunk extensor endurance. Although participants of the present study could be considered as overweight based on their BMI $(26.6 \pm 6.3), 18.7 \%$ of the participants were obese (BMI>30). In UK, paramedics were found to have higher BMIs comparing the general population $\quad(27.10 \pm 4.30$ $\mathrm{kg} / \mathrm{m} 2 \quad$ vs. $26.47 \quad \pm 5.42$, $\mathrm{p}<0.001$ ) (13). For prevention purpose, all participants may need to improve their physical fitness especially, musculoskeletal trunk endurance. Some investigators studied the obesity epidemic and future emergency responders; they found that excess weight is highly prevalent and associated with lower exercise tolerance among 


\section{2}

future emergency responders (9). Furthermore, some studies concluded that carrying equipment and patients over long distances as part of the EMS daily occupational tasks may lead to injury including back injuries which may impede the sufficient of their work performance and have been identified as a problem within the profession $(5-7,20)$. Generally, the results of present study concur with a similar study done recently on the same sample (PSACEMS's students).

Consequently, any increase in body mass may elevate the risk of occupational injuries especially lower back injury. The participants of the present study still young and did not start working in the field yet. Thus, the (PSACEMS) should consider the importance to qualify their students by developing their physical fitness ability and to assess their improvement for occupational job in the future.
The statistic results indicated that there is a strong relationship between the trunk flexor endurance and the trunk extensor endurance. There are evidence suggests that the ability of the trunk muscles to maintain appropriate levels of activation over long periods may be more important than maximum strength in terms of protecting the passive structures of the lumbar spine from injury (1, 7). It has also suggested that sufficient trunk muscle endurance contributes to spinal stability over strenuous and prolonged physical tasks (9). There was a strong to moderate significant correlations between most of the variables. The results indicated that there is a strong agreement between the trunk flexor endurance and the trunk extensor endurance $(r=0.69, \mathrm{P}$ $<0.01)$. In addition, there are a strong correlation between trunk lateral endurance (left side) and trunk lateral endurance (right side) tests (r 
$=0.81, \mathrm{P}<0.01)$. a recent study concluded that "organizational and human determinants can be identified to better guide preventive measures" (10).

\section{Conclusion:}

In conclusion, the low physical fitness in core function for the students in this study alarming that they are at risk for injury after graduation and during they future occupational. Education and physical exercise intervention program emphasize on static balance and postural control and an overall flexibility and strength may be important for prevention of occupational risk to EMS students. A controlled investigation of such a prevention program would be very appropriate next step.

Acknowledgments

This research project supported by a grant from the research center for the sport science and physical activity college, deanship of scientific research at King Saud University. The authors thank Prince Sultan bin
Abdulaziz EMS College for their assistance in facilitating this study.

\section{Refferance}

1- Biering- Sørensen F. Physical measurements as risk indicators for low-back trouble over a one-year period. Spine 1984; 9 (2):106-19.

2- Black, F.O. et al. Normal subject postural sway during the Romberg test. American Journal of Otolaryngology 1982; 3, 309-318.

3- Bureau of Labor Statistics, U.S. Department of Labor, Occupational Outlook Handbook, 2014-15 Edition, EMTs and Paramedics, on the Internet

at http://www.bls.gov/ooh

/healthcare/emts-and-

paramedics.htm (Visited March 2nd , 2019).

4- Crill MT, Hostler D. Back strength and flexibility of EMS providers in practicing prehospital providers. J Occup ehabil 2005; 15:105-111.

5- Despres, J.P. Health consequences of visceral 
obesity. Annals of Medicine 2001; 33, 8,534-541.

6- Gershon RR, Vlahov D, Kelen G, Conrad B, Murphy L. Review of accidents/injuries among emergency medical services workers in Baltimore, Maryland. Prehospital Disaster Med 1995; 10:14-18.

7- Hogya PT, Ellis L. Evaluation of the injury profile of personnel in a busy urban EMS system. Am J Emerg Med 1990; 8:308-311.

8- Jones AY, Lee RY. Cardiopulmonary resuscitation and back injury in ambulance officers. Int Arch Occup Environ Health 2005; 78:332336.

\section{9- Koumantakis GA, Watson} PJ, Oldham JA. Supplementation of general endurance exercise with stabilisation training versus general exercise only: physiological and functional outcomes of a randomised controlled trial of patients with recurrent low back pain. Clin Biomech 2005; 20(5):474-82.
11- Larouche, D., Bellemare, M., Prairie, J., Hegg-Deloye, S., \& Corbeil, P. (2019). Overall risk index for patient transfers in total assistance mode executed by emergency medical technician-paramedics in real work situations. Applied ergonomics, 74, 177-185.

12- Lavender SA, Conrad KM, Reichelt PA, Johnson PW, Meyer FT. Biomechanical analyses of paramedics simulating frequently performed strenuous work tasks. Appl Ergon 2000; 31:167-177.

13- Lentz, L., Randall, J. R., Gross, D. P., Senthilselvan, A., \& Voaklander, D. (2019). The relationship between physical fitness and occupational injury in emergency responders: A systematic review. American journal of industrial medicine, 62(1), 3-13.

14- MacQuarrie, A. J., Robertson, C., Micalos, P., Crane, J., High, R., Drinkwater, E., \& Wickham, J. 
(2018). Fit for duty: The health status of New South Wales Paramedics. Irish Journal of Paramedicine, 3(2).

15- S.M. McGill, S. Grenier, N. Kavcic, J. Cholewicki. (2003). Coordination of muscle activity to assure stability of the lumbar spine. J. Electromyogr. Kinesiol., 13 pp. 353-359.

\section{6- McGill, S. Low Back}

Disorders: Evidence Based Prevention and Rehabilitation (2nd ed.). Champaign, Ill.: Human Kinetics. 2007.

17- National Association of Emergency Medical Technicians (NAEMT). EMS Health and Safety: EMS Fitness 2012. www.naemt .org/emshealthsafety/EMSFitne ss.aspx. (Visited March 2nd, 2019).

18- Newton, R. Review of tests of standing balance abilities. Brain Injury 1989; 3, 4, 335-343.
19- Reichard, A., Marsh, S., \& Moore P. Fatal and nonfatal injuries among emergency medical technicians and paramedics. Prehospital Emergency Care 2011; 15, 511-517.

20- Schwartz RJ, Benson L, Jacobs LM. The prevalence of occupational injuries in EMTs in New England. Prehospital Disaster Med 1993; 8:45-50.

\section{1- Stilwell JA, Stilwell PJ.}

Sickness absence in an ambulance service. J Soc Occup Med 1984; 34: 96-99.)

22- Tsismenakis, A. J., Christophi, C. A., Burress, J. W., Kinney, A. M., Kim, M., \& Kales, S. N. The obesity epidemic and future emergency responders. [Research Support, U.S. Gov't, Non-P.H.S.]. Obesity (Silver Spring), 2009;17(8), 1648-1650. Doi: $10.1038 /$ oby.2009.63. 